ISSN electrónico: 1885-5210

DOI: https://doi.org/10.14201/rmc202016e263270

\title{
UNA ESPERANZA MUY SANGUÍNEA PARA ESTOS TIEMPOS DE PANDEMIA
}

\section{A Quite Bloody Hope for these Pandemic Times}

\section{Oscar BOTTASSO}

Instituto de Inmunología Clínica y Experimental de Rosario (Universidad Nacional de Rosario-Consejo Nacional de Investigaciones Científicas y Técnicas), Rosario (Argentina).

Correo electrónico: bottasso@idicer-conicet.gob.ar

Fecha de recepción: 22 de junio de 2020

Fecha de aceptación: 29 de julio de 2020

Fecha de publicación: 29 de enero de 2021

\section{Resumen}

El artículo hace referencia al desarrollo histórico de las terapias de inmunidad pasiva en enfermedades infecciosas y su actual aplicabilidad a los pacientes afectados por COVID-19. En paralelo también realiza un enfoque desde el costado humanístico que involucra la donación de sangre, sumado al profundo simbolismo conferido por distintas culturas respecto a este elemento tan vital.

Palabras clave: COVID-19; pandemia; plasma de convalecientes; inmunidad pasiva.

\section{Abstract}

The article deals with the historical development of passive immunity therapies in infectious diseases and their present applicability to COVID-19 patients. In parallel, it also performs an approach from the humanistic edge involving blood donation, along with the deep symbolism conferred by different cultures concerning this vital element.

Keywords: COVID-19; pandemic; convalescent plasma; passive immunity. 
La ciudad, como tú mismo puedes ver, está ya demasiado agitada y no es capaz todavía de levantar la cabeza de las profundidades por la sangrienta sacudida. Se debilita en las plantas fructiferas de la tierra, en los rebaños de bueyes que pacen y en los partos infecundos de las mujeres. Además, la divinidad que produce la peste, precipitándose, aflige la ciudad. iOdiosa epidemia, bajo cuyos efectos está despoblada la morada Cadmea, mientras el negro Hades se enriquece entre suspiros y lamentos! ${ }^{a}$

\section{CULTURA, CIENCIA, SANGRE Y ENFERMEDAD}

Desde tiempos inmemoriales la sangre ha tenido un profundo significado, independientemente de la cultura que se trate; el cual se extiende mucho más allá de su componente biológico. Varios pueblos antiguos asimilaban a esta como el asiento del alma, o una especie de elemento divino. Las ofrendas de sangre animal o humana a una deidad constituían, incluso, un ceremonial en muchos ritos arcaicos. En el mismo culto de Cibeles durante la época del Imperio Romano, los creyentes ingerían o eran vertidos con la sangre de los toros sacrificados, cuyo tono vivificante debían supuestamente adquirir.

El componente místico de la sangre impregna, igualmente, el pensamiento cristiano, como aparece claramente reflejado en el evangelio de Juan cuando Jesús refiere: "Si no comes la carne del Hijo del Hombre y no bebes su sangre, no tienes vida dentro de ti".

La sangre crea lazos muy fuertes y en definitiva nos hermana.

Sabedor de este profundo simbolismo, Goethe pone en boca de Mefistófeles aquellas famosas palabras dirigidas a Fausto en momentos de sellar el pacto, "La sangre es un humor muy especial".

De un modo hasta casi inusitado para la jerga investigativa esta expresión fue utilizada en la conclusión de un trabajo que Emil von Behring (1854-1917) y Shibasaburo Kitasato (1853-1931) publicaron en 1890 en el cual concluyen "Los resultados de nuestros experimentos nos recuerdan a viva fuerza estas palabras: Blut ist ein ganz besonderer Saft" ${ }^{\prime \prime}$.

Las derivaciones que pueden adoptar tal o cual hecho científico son a menudo imprevisibles; y aquí tenemos un claro ejemplo. Lo que sigue a partir de este estudio fundacional, es una serie de hechos concatenados cuya resultante aparece como una posibilidad cierta de aportar soluciones para la actual pandemia.

El trabajo que estos investigadores habían publicado en Alemania ${ }^{1}$, hacía referencia a experimentos de inmunización con bacilos tetánicos virulentos en conejos, a quienes se les recogía sangre de la arteria carótida para ser inyectada en la cavidad abdominal de ratones; a su vez desafiados con este microorganismo. Los resultados indicaban que este procedimiento era capaz de neutralizar tanto los bacilos como la toxina tetánica, y que dicha propiedad también se lograba al inocular suero libre de células. Dicho efecto protector no se conseguía si se empleaba sangre de animales no inmunes al Clostridium tetani.

Una semana después, aparece otro artículo en la misma revista bajo la única autoría de von Behring sobre inmunidad hacia la difteria en animales. En el mismo propuso algo similar, sin informar inextenso los experimentos respaldatorios; los cuales se habían llevado a cabo en cobayos puesto que los ratones y las ratas eran naturalmente inmunes al Corynebacterium diphtheriae ${ }^{2}$.

a. Súplica del Sacerdote. Sófocles: Edipo Rey.

b. La sangre es un jugo/humor muy especial.

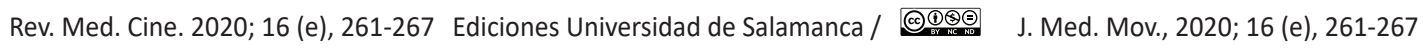


Behring comenzó el primer ensayo humano de terapia sérica antidiftérica en enero de 1892. La prueba logró un éxito limitado debido a una calidad inapropiada del suero. Por suerte, el procedimiento fue perfeccionado a partir de la utilización de mamíferos grandes y el desarrollo de técnicas de estandarización a cargo de Paul Ehrlich (1854-1915). En un informe elaborado en 1894, en 220 niños que sufrían de difteria se señala una remisión global del $77 \%$. Si la terapia comenzaba en los primeros 2 días después del diagnóstico de la enfermedad el éxito era casi del $100 \%$, mientras que para el día 6, la protección alcanzaba al $50 \%$. En realidad, Behring y Ehrlich adoptaron una modalidad utilizada por Émile Roux (1853-1933) y Alexandre Yersin (1863-1943) quienes, tras caracterizar la toxina diftérica en 1888 , decidieron inmunizar caballos para la posterior obtención de sueros.

El tétanos también constituía un foco de atención y si bien los primeros intentos de intervención fueron bastante decepcionantes, en 1895, Edmond Nocard (1850-1903) dio a conocer una terapia sérica exitosa al tratar a este tipo de animales con dicha enfermedad. La Primera Guerra Mundial constituyó el escenario que posibilitó implementar la aplicación de suero equino a soldados con heridas tetanígenas, con resultados sumamente eficaces en términos de reducción de la tasa de mortalidad.

La epidemia de gripe de 1918 sumó por su parte una innovación, como fue la administración de plasma de convalecientes, y el consecuente descenso en el número de casos fatales ${ }^{4}$. Treinta años después el epicentro se corre a la pampa argentina, concretamente a mediados de la década del 50. Básicamente se trataba de una extraña dolencia que algunos denominaban "Gripe Italiana" de curso bastante sombrío, la cual afectaba fundamentalmente a habitantes de zonas rurales. El común de la gente hablaba de "la fiebre"; mientras que los médicos de la región pensaban que se trataría de una influenza atípica, fiebre tifoidea, hepatitis, leptospirosis o quizás una encefalitis post-gripal.

Para el Dr. Rodolfo Arribálzaga de la localidad de Bragado en la provincia de Buenos Aires, el cuadro clínico que presentaban estos pacientes no parecía encajar con ninguna de las patologías infecciosas ya conocidas. Se tornaba imprescindible recabar más datos, y así decidió abocarse al estudio clínico pormenorizado de esta dolencia. Tras unos años de intensa labor en 1955 publica un artículo titulado "Una nueva enfermedad epidémica a germen desconocido: hipertermia, nefrotóxica, leucopénica y enantemática" ${ }^{5}$. Tiempo después supimos que la Fiebre Hemorrágica Argentina (FHA) estaba ocasionada por un Arenavirus, el virus Junín, y que su reservorio natural es el ratón transmisor del agente a través de la saliva, orina o sangre. Librada a su curso natural, la enfermedad exhibía una mortalidad que rondaba el $30 \%$. Siempre en la provincia de Buenos Aires, pero ahora ubicados en la ciudad de Pergamino, un equipo de salud liderados por el Dr. Julio Maiztegui, dicho sea de paso, otro hijo de vascos efectuó un estudio de inmunoterapia pasiva entre los años 1974 y 1978 en 188 pacientes con FHA. Estos fueron asignados al azar para recibir por vía intravenosa $500 \mathrm{ml}$ de plasma inmune (obtenido de convalecientes de FHA, en quienes se había demostrado un aumento de cuatro veces o más en los títulos de anticuerpos hacia el virus) o plasma de donantes residentes fuera del área endémica de la enfermedad. De 91 que recibieron plasma murió 1 mientras que en los 97 receptores de plasma no inmune fallecieron $16^{6}$. En una segunda publicación ${ }^{7}$ donde se combinaban datos de un estudio retrospectivo (1978-1981) con otro prospectivo (epidemias de 1982 y 1983), procedieron a titular los niveles de anticuerpos neutralizantes contra el virus Junínc; y pudieron demostrar que los plasmas con mayores niveles de unidades neutralizantes conferían mayor protección al ser administrados a los enfermos de $\mathrm{FHA}^{7}$. 
El nuevo milenio trajo consigo dos nuevas epidemias, ambas ocasionadas por coronavirus, y que también presentaban desenlaces fatales, el síndrome respiratorio agudo severo (SARS-CoV-1, 2003) y tiempo después el síndrome respiratorio de medio oriente (MERS, 2012). En un estudio llevado a cabo en Hong Kong entre 80 pacientes de SARS-CoV-1, aquellos tratados dentro de los primeros 14 días de infección tuvieron un alta hospitalaria más temprana ${ }^{8}$. Como un último antecedente, unos años después también se aplicó esta modalidad en los afectados de gripe H1N1. Las reducciones en mortalidad por esta inmunointervención, según las dos investigaciones, fluctuaba entre un $50 \%$ y $70 \%{ }^{8,9}$.

$Y$ en este trajinar pestilente, ahora nos ha tocado florearnos con el coronavirus 2019 (COVID-19). Si nos detenemos a contemplar el camino andado, el historial es auspicioso para avizorar un beneficio cierto tras la administración de plasma convaleciente o un suero específico en aquellos pacientes que así lo requieran. Nos hemos apoyado en la cuarentena, el aislamiento, y medidas para la atención de los enfermos, pero el mundo aguarda nuevos tratamientos, por lo que las terapias pasivas han vuelto a estar en el

\section{Una historia de 130 años ${ }^{d}$}

Behring fue galardonado en 1901 con el Premio Nobel por su trabajo en Difteria. Por aquellos años, Ehrlich había anticipado una teoría según la cual los glóbulos blancos contaban con cadenas laterales en la membrana celular. Al tomar contacto con una toxina (antígeno), dichas cadenas debían liberarse al torrente sanguíneo para neutralizarla. También sugirió que estas estructuras presentes en la membrana plasmática podían inducir a que las células produjeran más de tales moléculas con la misma especificidad ${ }^{14-16}$. Ya entrado el siglo XX, se pudo demostrar que el suero protector podía neutralizar y precipitar toxinas a la par de aglutinar bacterias. El compuesto responsable de estas acciones se denominó antitoxina, precipitina o aglutinina, distintos nombres para una misma sustancia. En 1939, Tiselius y Kabat señalaron que los anticuerpos eran gama-globulinas ${ }^{17}$. Linus Pauling a su vez confirmó la teoría de cerradura y llave propuesta por Ehrlich al constatar que las interacciones entre anticuerpos y antígenos dependían más de su forma que de su composición química ${ }^{18}$. Varios años después, Astrid Fagraeus refirió que las células plasmáticas $B$ eran las responsables de la generación de anticuerpos ${ }^{19}$. Burnet, por su parte, propuso en 1957 que las células productoras de los mismos lo hacían con una única especificidad, determinada antes del encuentro con el antígeno. Sin embargo, cuando estas células contactaban con el inmunógeno en cuestión, podían dividirse y aumentar selectivamente la disponibilidad de dicho anticuerpo ${ }^{20}$. Por esos mismos años, Nossal y Lederberg confirmaron que los plasmocitos sintetizaban inmunoglobulinas con especificidad contra un antígeno ${ }^{21}$; mientras que otros grupos identificaron los tres fragmentos de la molécula, dos correspondientes a los Fab (unión a antígeno) y el restante al Fc (cristalizable)22. En 1975, Kohler y Milstein encontraron la clave para la elaboración de anticuerpos monoclonales ${ }^{23}$, con lo cual aquellas balas mágicas propuestas por Ehrlich cobraron nuevos bríos.

c. Monocapas de células vero, infectadas con la cepa atenuada $\mathrm{XJ} \mathrm{Cl} 3$ del virus Junín, donde se agregaban distintas diluciones del plasma para la titulación de las unidades neutralizantes.

d. Un relato pormenorizado sobre el historial de los anticuerpos excede a los propósitos de este escrito, pero puede consultarse en un artículo muy informativo al respecto ${ }^{24}$. 
tapete. Sabemos de la labor orientada a obtener gamma globulinas hiperinmunes, y por ende mucho más efectivas. En paralelo existen algunos estudios no controlados en cuanto al uso de plasma convaleciente en pacientes con COVID-19 que apuntan a un posible beneficio ${ }^{10-12}$. Hace muy poco, investigadores chinos llevaron a cabo el primer ensayo clínico aleatorizado en enfermos de esta naturaleza ${ }^{13}$, donde se utilizaron unidades de plasma con un alto título de anticuerpos hacia SARS-CoV-2. Lamentablemente el ensayo concluyó antes de lo previsto por lo que el poder del estudio resultó inadecuado. A pesar de ello, los resultados sugieren una situación más favorable en los tratados con plasma de convaleciente. Los meses venideros seguramente nos brindarán datos mucho más informativos respecto a las fortalezas y debilidades de este tipo de intervención.

Aquel conocido adagio de "paciencia ante la urgencia" sigue siendo plenamente válido. Abocarnos a una "ciencia rápida" entraña el riesgo de no hacerla bien, ergo nada de apresuramientos y desprolijidades.

\section{LA ESPERANZA, UN PODEROSO MOTOR}

La donación es un acto de generoso desprendimiento y profunda solidaridad en favor de otra persona con miras a que resulte favorecida. Visto desde la situación de enfermedad, emerge como una semilla de esperanza, capaz de avivar esa tan necesaria confianza en torno a una pronta recuperación.

El arte que tanto ha contribuido a ilustrar estas vivencias nos muestra un ejemplo palmario en la persona de Frida Kahlo. Postrada con su salud en franco deterioro y ante el fracaso de una intervención quirúrgica, orientada a fortalecer su columna vertebral, la artista consigue plasmar en sus lienzos las emociones encontradas que por entonces poblaban su alma: La columna rota (1944), Sin esperanza (1945), El ciervo herido (1946) y esa suerte de grito Árbol de la esperanza mantente firme (1946, Foto 1).
Los hacedores de la gran música nos han regalado, por su parte, muchas páginas que inspiran consuelo, y ayudan a mitigar el dolor físico o espiritual. La lista sería interminable y cada uno confeccionará la suya propia. Particularmente uno se siente entre algodones al oír el Ave verum corpus de Mozart, el coro a boca cerrada de Puccini, el adagio de la segunda sinfonía de Rachmaninoff, o ese otro escrito por Albinoni, como así también el andante de la sonata para flauta BWV 1034 del genio de Eisenach, o La mañana de la Suite para Peer Gynt de Edvard Grieg. Clásicos para la esperanza diría yo.

Atesoremos pues muy bien aquellas palabras de San Pablo: "Hay tres cosas que permanecen: la fe, la esperanza y el amor" (1Co 13:13). En la mesa de vida frecuentemente se sirven los sufrimientos, pero todo se vuelve más llevadero

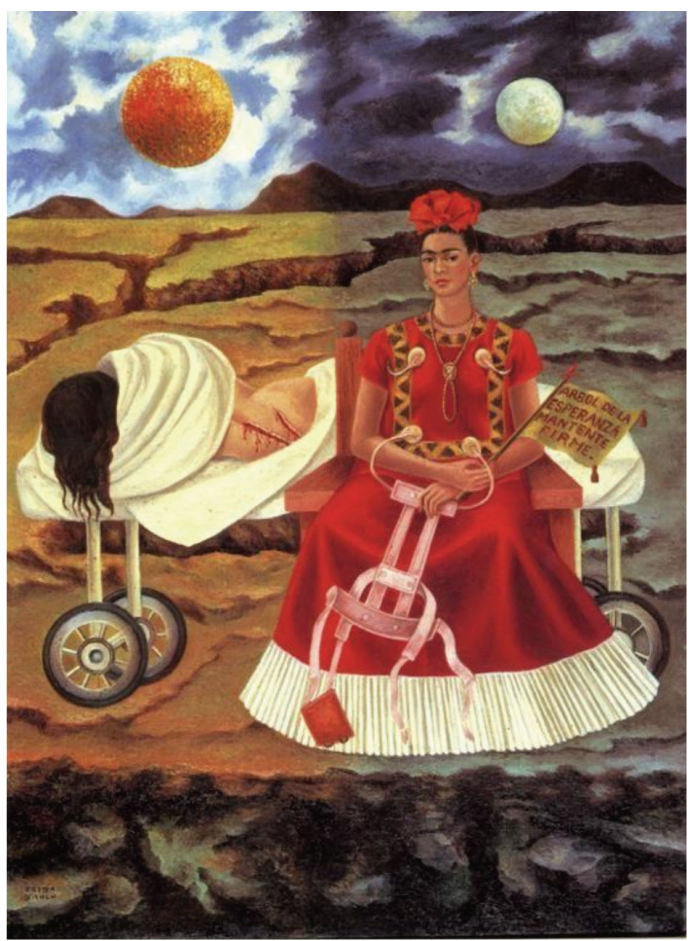

Foto 1. Frida Kahlo: Árbol de la esperanza (1946). https://www.freeart.com/gallery/k/kahlo/kahlo66.html 
cuando nuestro corazón se abre para que anide ese soplo vivificante.

La Medicina lo tuvo en cuenta desde sus comienzos. Al referirse a la existencia de fuerzas curativas intrínsecas dentro de cada uno de nosotros, Hipócrates sostuvo que le cabía al médico el favorecer esas potencias naturales tanto por medios físicos como psicológicos. Para esto último, el alma debía reposar y fortalecerse mediante el consuelo y la esperanza. Nihil addendi.

Y para ir cerrando esta apretada síntesis "occidental" es claro que la mitología tampoco se quedó en la zaga. Según las crónicas, el enojo de Zeus con Prometeo por haberle robado el fuego hizo que le obsequiara a Pandora, cuñada del arrebatador, una caja en la que se hallaban contenidos todos los males del mundo. Presa de una peculiar curiosidad, Pandora procedió a abrirla y al advertir que todas las desgracias eran liberadas, la cerró rápidamente, logrando que la esperanza no se escapara,... para suerte de todos los mortales que le hemos sucedido.

La pandemia COVID-19 es un eslabón más en la cadena de infortunios a las que han estado expuesto los seres humanos en su largo transitar por este mundo. El conocimiento y posibilidades tecnológicas con las que hoy contamos, son buenas razones para abrigar la esperanza de que en un mediano plazo contaremos con herramientas posibilitadoras de un control más racional y efectivo de la situación. La trama da sin embargo para mucho más; COVID-19 también es una encrucijada que nos convoca a tomar debida nota de nuestro accionar ante una situación cuya respuesta no sólo involucra el componente biomédico sino todas las facetas que hacen a la problemática Salud-Enfermedad-Atención. Bueno sería que tras su resolución el mundo haya escalado hacia una condición ética y moralmente más decorosa.

\section{REFERENCIAS}

1. Behring E, Kitasato S. Über das Zustandekommen der Diphtherie-Immunität und der Tetanus-Immunität bei Thieren. Dtsch Med Wschr 1890; 49:1113-4.

2. Behring E. Untersuchungen ueber das Zustandekommen der Diphtherie-Immunität bei Thieren. Dtsch Med Wschr 1890; 50: 1145-8.

3. Behring E. Die Geschichte der Diphtherie (mit besonderer Berücksichtigung der Immunitätslehre). Verlag von Georg Thieme, Leipzig: Verlag von Georg Thieme 1893.

4. Luke TC, Kilbane EM, Jackson JL, and Hoffman SL. Meta-analysis: convalescent blood products for Spanish influenza pneumonia: a future $\mathrm{H} 5 \mathrm{~N} 1$ treatment? Ann Intern Med 2006;145(8): 599-609.

5. Arribalzaga, RA. Una nueva enfermedad epidémica a germen desconocido: hipertermia, nefrotóxica, leucopénica y enantemática. El Día Médico (Buenos Aires) 1955; 27: 1204-10.

6. Maiztegui JI, Fernandez NJ, de Damilano AJ. Efficacy of immune plasma in treatment of argentine hæmorrhagic fever and association between treatment and a late neurological syndrome. Lancet 1979; 2(8154):1216-7.

7. Enria DA, Briggiler AM, Fernandez NJ, Levis SC, Maiztegui JI. Importance of dose of neutralising antibodies in treatment of argentine haemorrhagic fever with immune plasma. Lancet 1984; 2(8397):255-6.

8. Cheng Y, Wong R, Soo YOY, Wong WS, Lee CK, Ng $\mathrm{MHL}$, et al. Use of convalescent plasma therapy in SARS patients in Hong Kong. Eur J Clin Microbiol Infect Dis 2005; 24(1): 44-6.

9. Hung IF, To KK, Lee CK, Lee KL, Chan K, Yan WW, et al. Convalescent plasma treatment reduced mortality in patients with severe pandemic influenza $A$ (H1N1) 2009 virus infection. Clin Infect Dis 2011; 52(4): 447-56.

10. Duan K, Liu B, Li C, Zhang H, Yu T, Qu J, et al. Effectiveness of convalescent plasma therapy in severe COVID-19 patients. Proc Natl Acad Sci USA 2020; 117(17): 9490-6.

11. Shen C, Wang Z, Zhao F, Yang Y, Li J, Yuan J, et al. Treatment of 5 critically ill patients with COVID-19 with convalescent plasma. JAMA 2020; 323(16): 1582-9. 
12. Zhang B, Liu S, Tan T, Huang W, Dong Y, Chen L, et al. Treatment with convalescent plasma for criticaIly ill patients with severe acute respiratory syndrome coronavirus 2 infection. Chest 2020; 158(1):e9-e13.

13. Li L, Zhang W, Hu Y, Tong X, Zheng S, Yang J, et al. Effect of convalescent plasma therapy on time to clinical improvement in patients with severe and life-threatening COVID-19: a randomized clinical trial. JAMA. 2020: e2010044.

14. Ehrlich P. Experimentelle untersuchungen über immunität. Dtsch Med Wschr 1891; 17: 976-9.

15. The Nobel Prize in Physiology or Medicine 1908. NobelPrize.org.

16. Zielinska E. Side-chain theory, circa 1900. The Scientist [Internet]. Jun 30, 2013.

17. Tiselius A, Kabat EA. An electrophoretic study of immune sera and purified antibody preparations. J Exp Med 1939; 69(1):119-31.
18. Pauling L. A theory of the structure and process of formation of antibodies. J Am Chem Soc. 1940; 62:2643-57.

19. Kugelberg E. Milestone 3: searching for the antibody producers. Nat Milest Antib. 2016; S7. 10.1038/ni.3602

20. Burnet FM. A modification of Jerne's theory of antibody production using the concept of clonal selection. CA Cancer J Clin. 1976; 26(2): 119-21.

21. Nossal GJV, Lederberg J. Antibody production by single cells. Nature. 1958; 181(4620):1419-20.

22. Porter RR. The hydrolysis of rabbit $y$-globulin and antibodies with crystalline papain. Biochem J. 1959; 73(1):119-26.

23. Kohler G, Milstein C. Continuous cultures of fused cells secreting antibodies of predefined specificity. Nature. 1975; 256(5517):495-7

24. Black CA. A brief history of the discovery of the immunoglobulins and the origin of the modern immunoglobulin nomenclature. Immunol Cell Biol. 1997; 75(1):65-8.

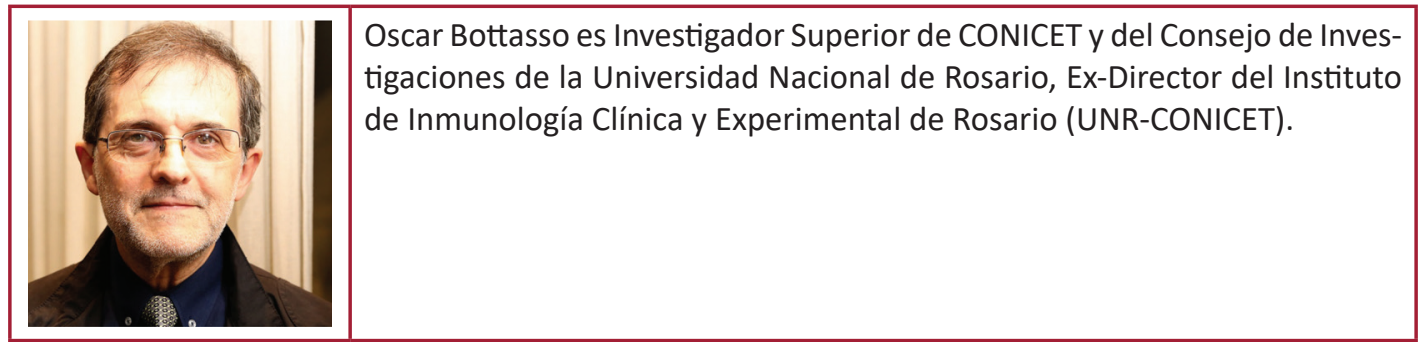

Rev. Med. Cine. 2020; 16 (e), 261-267 Ediciones Universidad de Salamanca / @®@@ J. Med. Mov., 2020; 16 (e), 261-267 